\title{
Land and People.
}

The Russian Colonization of the Kazak Steppe

\author{
by
}

Gulnar Kendirbai 
